\title{
Dynamics of economic growth and Environmental Degradation in Nigeria using Vector Auto-regressive model
}

\author{
Timothy O. Olatayo ${ }^{1 *}$, Mayor Andrew ${ }^{2}$, Moses C. Ekperiware ${ }^{3}$ \\ ${ }^{1}$ Department of Mathematical Sciences, \\ Olabisi Onabanjo University, Ago-Iwoye, Nigeria \\ ${ }^{2}$ Delta State Polytechnic, Ote-Ofe \\ Oghara, Nigeria \\ ${ }^{3}$ Technology Management (NACETEM), Obafemi Awolowo University \\ Ile-Ife, Nigeria \\ *Corresponding author's email: Bisi.olatayo [AT] oouagoiwoye.edu.ng
}

\begin{abstract}
The study examined the interrelationship among economic growth, environmental pollution and human health for Sustainable Development (SD) in Nigeria. This was to contribute to the dynamic debate of how human and economic activities relate and interrelate with environmental pollution in measuring sustainable development in Nigeria. This study further sought to verify the Environmental Kuznet Curve Hypothesis in Nigeria.

The study employed the Vector Error Correction Model (VECM) to investigate linear and interrelationship mainly among life expectancy at birth, economic growth and environmental pollution in Nigeria from 1970-2015. Since the variables have unit root and revealed that there is at least a cointegrating equation in the model, the VECM become a more appropriate model for the study.

The VECM Impulse Response Function (IRF) result indicated that economic growth increased environmental degradation in the long run and environmental degradation on the other way round reduced economic growth in most of the period of the study. The VECM system conditional forecast of 10\%, 20\% and 26\% from 2000 to 2015 periods showed that a $10 \%, 20 \%$, and $26 \%$ reduction forecasts of environmental pollution led to a consistent increased economic growth and life expectancy at birth of the country in the study. This indicated that a reduction in environmental pollution will improve the health of Nigerians and also enhance a sustainable development in the country.

The study concluded that environmental degradation reduces economic growth while economic activities in the country increases environmental degradation in the country. From the conditional forecast, the study further concluded that efforts in reducing environmental pollution through policies and better environmental friendly economic activities will improves economic growth for sustainable development in the country.
\end{abstract}

Keywords---- Environmental pollution, population, sustainable development, vector error correction model, environmental kuznet curve hypothesis

\section{INTRODUCTION}

The relationship among human and economic activities with respect to the given environment has been interesting even from different discipline for sustainable development. How nations can go on with their economic activities with little or no disruption of the environment is increasingly gaining momentum. An atmosphere where the future generation is not jeopardized is indisputably essential. The popular Environmental Kuznets Curve (EKC) hypothesis is a handy point of reference [1]. Studies have shown that economic activities have definite impact on the environment and vice versa how the environment affects economic activities [2]. The overriding concept is that the environment provides the critical basis for development through man's intermediation.

The World Health Organisation (WHO) has ranked the urban environmental pollution the 13th contributor to global deaths in its 2002 World Health Report. Environmental pollution is the largest emission source of many health-related environmental pollutants such as carbon monoxide CO (59\%) and nitrogen oxides NOx (45\%), benzene (32\%), 1,3butadiene $(75 \%)$ and primary $\mathrm{PM}_{10}(25 \%)$, some of which contribute to the formation of ozone $\left(\mathrm{O}_{3}\right)$ and secondary particles

In the Nigerian context, these claims need to be substantiated from dynamic points of view with recent data using the vector-autoregressive model. Economic activities such as manufacturing and constructions to mention a few have direct 
effect on the ecosystem but the nature of effect with respect to sustainable development is debatable. It is now generally accepted that many health problems (e.g., respiratory and cardiovascular) can be caused or worsened by exposure to environmental pollution on a day-to-day basis. Activities of oil spill in the Niger delta, especially the Ogoni Oil Spill is an example of one of these cases. Pollution from other industrial activities like manufacturing with less compliance to environmental laws also contribute to environmental pollution and goes a long way in contributing to reduction in life expectancy at birth in the country. It is expedient that a holistic economic plan that involves all stakeholders to capture economic activities and environmental protection to ensure sustainable development is put in place $[3,4)]$ In addition, the connection between economic activities and the environment is symbiotic, as what affects one transmits to affect the others [5]. Most of the fallout of the hazards of economic activities on environmental pollution results in poor health, especially in populous nations like Nigeria.

From the aforementioned discuss, increasing success has been made in capturing the dynamics of sustainable development from weak to strong sustainable development [6]. Present concern is how economic activities do not increase environmental degradation, and how these relationships affect human life in the country. Therefore, there is a great need to monitor high levels of pollutant concentrations in conjunction with meteorological data, with the aim of developing adequate time series stochastic methods in order to understand the complex mechanism involved in the formation of elevated environmental pollution concentrations. Several statistical methodologies like using regression models have been suggested to model environmental pollution [7;8]. However, a theoretical econometric methodology that can capture transmission and feedback effects is essential. More so, a statistical model that can envisage a scenario of likely policy effect of environmental pollution and economic growth in the country is indispensable.

Studies have shown how economic growth can sufficed environmental degradation according to the EKC model in that economic growth reduces environmental degradation with time [9] but how true is the Nigerian case in recent time given increasing economic activities on the fix environment in Nigeria. Hence, this study investigate the relationships and interrelationship between economic activities and environmental pollution with respect to sustainable development in Nigeria from 1970 to 2015 .

\section{LITERATURE REVIEW}

The importance of taking stock of past works relating to human, economic and environmental pollution is germane to position the direction of this research exercise in contributing to the body of knowledge. Hence, some selected past studies are appraised in areas of current trends, research objectives, scopes, methods and findings to be better acquainted and positioned properly in the literature which are presented here. [10] predicted the occurrence, level and duration of high air pollution concentrations exceeding a given critical level. This was to enable examining the health impact of road traffic on local air quality and to inform public policy action. Extremes of nitrogen oxide (NO), nitrogen dioxide (NO2) and ozone (O3) concentrations are investigated using threshold and a special functional form for the GPD parameters models. Precise estimates of the probabilities of occurrence and level of extreme concentrations are formidable due to the combination of complex physical and chemical processes involved.

[11] investigated the frequency of respiratory health symptoms among high school students attending schools at industrial, urban and rural areas in a Turkish city. The study revealed that chronic pulmonary disease, tightness in the chest and morning cough were higher among students in the industrial zone where nitrogen dioxide and ozone levels were also highest.

[12] examined the role of environmental quality and income in determining health expenditures for the period of 1967 to 2010 in Iran. They used cointegration and ARDL approach in order to explore the possibility of estimating both short-run and long-run impacts of environmental quality. They finding showed that health expenditure, income, sulphur oxide emissions and carbon monoxide emissions are cointegrated. The findings further indicated that short-run and long run elasticity of income, sulphur oxide emissions and carbon monoxide emissions exert a statistically significant positive effect on health expenditures.

Similarly, [13] examined damages from nitrogen, phosphorous, sediment and pesticide residues on sea grasses and coral and subsequent negative impacts on commercial fishing and tourism, using the multi-criteria approach, which typically integrates criteria scores into a single value. The study modified the approach to compare river basins and their contribution to pollution discharge, rather than to compare alternative actions. The criteria (ecological impact of pollution, social impact of pollution prevention and economic impacts of pollution) were scored and weighted. The results showed that scoring of individual river basins led to an expert rating (low, medium, medium high, high) of the likely level of impact against each of the criteria, and this provided insights into both the urgency needed to curb diffuse-point pollution, and type of management mechanisms to adopted in achieving pollution reduction. The approach identified the magnitude of the hazard, the focus area for management and information about the human dimension of the issue. 
Looking at the relationship between environmental pollution and economic growth, [14] examined the impact of oil production on human condition in Nigeria. They studied the relationship among environmental degradation, life expectancy, and infant mortality rate in Nigeria from 1980 to 2012. The data were obtained from the statistical bulletin of the Central Bank of Nigeria and World Development Indicator. Vector autoregressive (VAR) model and variance decomposition analysis were explored. The study found three striking results: (i) oil production of the first period positively impacted environmental degradation while it was negative in the second period; (ii) Its first period lag has positive relationship but second period lag has negative relationship with life expectancy; and (iii) the variance decomposition analysis showed that oil production worsened environmental degradation and adversely impacted on infant mortality rate, while it positively affected life expectancy. However, the study did not look at how environmental pollution affects the rate of death in the country due to high rate of environmental pollution related diseases. More so, the analysis did not emphasis the feedbacks from these variables in the study besides capturing only oil production, leaving out other forms of economic activities that cause pollution.

[15] also examined the relationship between environmental pollution and economic growth. The study showed that the positive link between pollution and growth is intensified when including health aspects because pollution raises health costs which, in turn, foster precautionary savings and capital accumulation.

[16] further employed cross sectional data and GDP in nominal US \$ (1985) to examine the relationship between GDP and environmental pollution. The equations for the pollutants considered were logarithmic quadratics in income per capita. Deforestation was estimated against a translog function in income and population density. All the curves estimated were inverted U's with turning point for deforestation at $\$ 823$ per capita confirming the EKC hypothesis.

[17] delved into the relationship between $\mathrm{CO}_{2}$ emission and GDP in Canada for the period of 1948-2004. They used parametric, semi-parametric and non-linear models estimation techniques. They found weak evidence of the EKC hypothesis for the relationship between $\mathrm{CO}_{2}$ emissions and GDP in the case of Canada.

[18] examined the Environmental Kuznets Curve (EKC) in the light of sulphur emission and income per capita. They calculated a much larger in size turning point (\$908178) compared with the total sample, implying a monotonic EKC. They used a global sample and an inverted U-shape function of income. The finding indicated that sulphur emissions per capita are a monotonic function of income per capita. [19] in another study investigated the main driving forces affecting short and long-run carbon emissions pattern due to changes in growth, inequality and poverty triangle in Pakistan over the period of $1980-2011$ using multivariate cointegration approach. The results indicated that on the short run, there is a significant negative relationship between economic growth \& carbon emissions, and economic growth \& poverty. The study also revealed there is a positive relationship between economic growth and income inequality; and poverty and income inequality. On the long-run, the study showed a significant positive relationship between GDP \& income inequality, carbon dioxide emissions and income inequality, and poverty \& income inequality in Pakistan. However, there was a negative relationship between carbon emissions and economic growth, carbon emissions and income inequality, and economic growth and income inequality. Hence, the results of Environmental Kuznets Curve (EKC) hypothesis showed an inverted U-shaped trajectory in relation to economic growth in Pakistan.

[20] examined the relationship between income and environment in the case of Turkey using time series and provincial panel data for the periods of 1968-2003 and 1992-2001 respectively. The panel analysis revealed a monotonically increasing relationship between carbon dioxide emissions and income in Turkey

On the relationship between human population and economic growth with environmental pollution,[21] examined the effect of aging population and public health funding (PHF) on savings and the growth rate of the economy. The study using a simple growth model, showed that an increase in life expectancy increases the growth rate in the economy without PHF. However, the relationship between life expectancy at birth and economic growth indicated an inverted U-shaped in the economy with PHF.

\section{MATERIALS AND METHOD}

The theoretical aspect of this study is based on the Environmental Kuznets Curve (EKC). The standard EKC regression model defined as

$$
\ln (E / P)_{i t}=\alpha_{i}+\gamma_{t}+\beta_{1} \ln G D P_{i t}+\beta_{2} \ln \left(G D P_{i t}\right)^{2}+\varepsilon_{i t}
$$

where $\mathrm{E}$ is emissions, $\mathrm{P}$ is population, (emission per capita) and ln indicates natural logarithms, while GDP is Gross Domestic Product. The first two components are intercept parameters which capture various regions $i$ and years $t$. In the study, the model is further specified based on the work of [1] as

$$
\ln (E / P)_{i t}=\alpha_{i}+\beta_{1} \ln G D P_{t}+\beta_{2} \ln \left(G D P_{t}\right)^{2}+\beta_{3} \ln \left(P O P_{t}\right)+\beta_{4} \ln \left(L E X P_{t}\right)+\varepsilon_{t}(3.2)
$$

where POP represents population and LEXP represents life expectancy at birth to capture effect of health related disease and death on environment. Conceptually, the EKC hypothesis was derived through data observation by plotting the variables. 
However, this study plug the variables of interest into atheoretical model where all the variables are endogenous variables, substantiating the effect of on each over time illustrated below [22].

\section{Vector autoregressive (VAR) models analysis}

The Vector Auto-Regression (VAR) model in this study is used to determine the interrelationships among GDP, environmental pollution, population, and life expectancy at birth in Nigeria. In addition, the VAR model, through VAR scenario analysis, will forecast the scenario effect of reduction of environmental pollution on GDP, population, and life expectancy at birth in Nigeria. From the theoretical equations: 3.1 and 3.2, the VAR model allows all variables to interact in the system model in providing for causal effects, impulse responses, forecast variance error decompositions, and scenario analysis, which are particularly important to this study [4]. The VAR model is a dynamic auto-regressive model that allows dynamic relationship than the normal static Ordinary Least Square (OLS) estimation.

$$
\operatorname{Var}(j) Y_{t}=\alpha+\phi_{1} Y_{t-1}+\cdots+\phi_{j} Y_{t-j}+\varepsilon_{t}
$$

Where $Y_{t}$ is a $4 \times 1$ vector of endogenous variables, $\alpha$ is a $4 \times 1$ vector of intercepts, $Y_{t-j}$ is a vector of lagged variables (exogenous in the study), with $\varepsilon_{t}$ as the disturbance terms, and $\phi$ is a $4 \times 4$ matrix of coefficients. Equation 3.3 represented in matrix form to be able to derive the standard VAR representation is thus:

$\operatorname{VAR}(1)\left[\begin{array}{c}G D P_{t} \\ E N V P_{t} \\ P O P_{t} \\ L E X P_{t}\end{array}\right]=\left[\begin{array}{c}\alpha_{1} \\ \alpha_{2} \\ \alpha_{3} \\ \alpha_{4}\end{array}\right]+\left[\begin{array}{llll}\phi_{11} & \phi_{12} & \phi_{13} & \phi_{14} \\ \phi_{21} & \phi_{22} & \phi_{23} & \phi_{24} \\ \phi_{31} & \phi_{32} & \phi_{33} & \phi_{34} \\ \phi_{41} & \phi_{42} & \phi_{43} & \phi_{44}\end{array}\right]\left[\begin{array}{c}G D P P C_{t-1} \\ E N V P_{t-1} \\ P O P_{t-1} \\ L E X P_{t-1}\end{array}\right]+\left[\begin{array}{c}\varepsilon_{1 t} \\ \varepsilon_{2 t} \\ \varepsilon_{3 t} \\ \varepsilon_{4 t}\end{array}\right]$

The matrix (equation 3.4) is specified further in a linear system as thus:

$$
\begin{aligned}
& G D P_{t}=\alpha_{1}+\phi_{11} G D P_{t-1}+\phi_{12} E N V P_{t-1}+\phi_{13} P O P_{t-1}+\phi_{14} L E X P_{t-1}+\varepsilon_{1 \mathrm{t}} \\
& E N V P_{t}=\alpha_{2}+\phi_{21} G D P_{t-1}+\phi_{22} E N V P_{t-1}+\phi_{23} P O P_{t-1}+\phi_{24} L E X P_{t-1}+\varepsilon_{2 t} \\
& P O P_{t}=\alpha_{3}+\phi_{31} G D P_{t-1}+\phi_{32} E N V P_{t-1}+\phi_{33} P_{t-1}+\phi_{34} L E X P_{t-1}+\varepsilon_{3 \mathrm{t}} \\
& L E X P_{t}=\alpha_{4}+\phi_{41} G D P_{t-1}+\phi_{42} E N V P_{t-1}+\phi_{43} P O P_{t-1}+\phi_{44} L E X P_{t-1}+\varepsilon_{4 t}
\end{aligned}
$$

Estimates of equations 3.5 to equation 3.8 can be summarised given that $p$ represents the number of lagged periods which is determined through the popular criteria on lag length criteria selection test and $Y$ the variables used in the model (as equation 3.3) as thus:

$$
\operatorname{VAR}(p) \approx \ddot{Y}_{t}=\alpha+\ddot{\phi}_{1} Y_{t-1}+\ddot{\phi}_{2} Y_{t-2}+\cdots+\ddot{\phi}_{p} Y_{t-p}
$$

The VAR technique will be applied to equation 3.9 where $p$ is equal to lag length. Testing for unit roots and lag length criteria are carried out to avoid spurious estimates [4]. A crucial assumption in using VAR is that the variables have to be stationary at levels. If the variables are not stationary but only stationary after first differencing them, then the Vector Error Correction Model (VECM) is the appropriate analytical model after checking for possibly long-run relationships among the variables (cointegration) $\phi$ in the $4 \times 4$ matrix captures the contemporaneous structure among the variables, for instance, how GDP relates with ENVP. The coefficients of the model are to reveal the impact of various shocks. If the VECM seems pliable given there is unit root in the variables, the short-run and long-run relationships among the variables would show how economic output relates with environmental pollution, population, and life expectancy at birth in Nigeria with likely feedback. The VECM presents the causal effects of variables in the model. It is an extension of VAR and it incorporates the possible cointegrating error term $\left(E C T_{t-1}\right)$ (into the built VAR model. VAR (j)

$Y_{t}=\alpha+\phi_{1} Y_{t-1}+\ldots+\phi_{j} Y_{t-j}+\pi E C T_{t-1}+\varepsilon_{t}$

The VAR or VECM model is useful in two regards in this study: forecasting and interpreting the relationships among variables. The impulse response functions (IRF), forecast error variance decomposition (FEVD), Multivariate Granger Causality (MGC), and the VAR Scenario Conditional Forecast Analysis (SCFA) show interpretation of innovation effects, causalities and forecasts. For instance, how much does economic growth causes environmental degradation in the Nigerian economy? 


\section{RESULTS AND DISCUSSION}

This section presents the results and findings of the study. These are; the relationships between environmental pollution and economic growth, the relationships between environmental pollution and life expectancy at birth, the relationships between environmental pollution and population and the scenario forecast of increase in environmental pollution in Nigeria.

The diagnostic tests shows that GDP, POP, LEXP and ENVP all have unit roots, at most 1 cointegrating equations at $5 \%$ level of significance with maximum lag length for the model of one shown in appendix 1, appendix 2 and appendix 3 respectively. Relying, therefore, on the presence of cointegrating series the study estimated a vector error correction model (VECM).

Interrelationship between Environmental Degradation and Economic Growth

The Impulse Response Function (IRF) result from table 4.1a indicates that environmental degradation (ENVP) responded negatively to economic activities in the country. However, in period 7 and 10, which is in the long run periods, economic activities led to a rise in ENVP in the country. This shows that economic activities affects ENVP (our cities) in the country. Negative effect of economic activities were mostly noticed in the long run unlike the findings of the famous Kuznet curve hypothesis $(\mathrm{KCH})$, where negative effect of economic activities on our cities were mostly in the short run and reduces in the long run.

A feedback effect from ENVP to GDP in table 4.1b shows that a shock on ENVP influences GDP negatively in most of the impulse periods except for the first, fifth and eight periods in the study. This indicates that ENVP reduces GDP which the Kuznet Curve Hypothesis did not investigate. In summary, economic activities increases ENVP in the long run and ENVP reduces GDP in most of the period.

Table 4.1a Impulse Response Function of Environmental Degradation in Nigeria

$$
E N V P_{t}=0.617679 G D P_{t-1}-0.20123 E N V P_{t-1}+2.750195 P O P_{t-1}+5.95702 L E X P_{t-1}
$$

\begin{tabular}{|l|l|l|l|l|}
\hline \multicolumn{2}{|l|}{ Response of LOG(ENVP): } & & \\
\hline Period & LOG(POP) & LOG(LEXP) & LOG(ENVP) & LOG(GDP) \\
\hline 1 & 0.00118 & -0.01343 & 0.19405 & $\mathbf{0 . 0 0 0 0 0}$ \\
\hline 2 & -0.04193 & 0.01779 & 0.14407 & $\mathbf{- 0 . 0 3 8 7 7}$ \\
\hline 3 & -0.01998 & 0.04493 & 0.16353 & $\mathbf{- 0 . 0 8 1 2 6}$ \\
\hline 4 & 0.10328 & 0.37705 & 0.12554 & $\mathbf{- 0 . 0 6 0 9 7}$ \\
\hline 5 & -0.14425 & -0.08116 & 0.13875 & $\mathbf{- 0 . 1 3 9 9 7}$ \\
\hline 6 & -0.20952 & -0.39701 & 0.09417 & $\mathbf{- 0 . 0 6 9 4 1}$ \\
\hline 7 & 0.55657 & 1.34806 & 0.06743 & $\mathbf{0 . 0 6 8 3 5 3}$ \\
\hline 8 & -0.43430 & -0.49470 & 0.26368 & $\mathbf{- 0 . 3 4 7 3 9}$ \\
\hline 9 & -0.93624 & -2.44435 & 0.09855 & $\mathbf{- 0 . 0 5 9 8 1}$ \\
\hline 10 & 2.750195 & 5.95702 & -0.20123 & $\mathbf{0 . 6 1 7 6 7}$ \\
\hline
\end{tabular}

Source: VECM result and Compiled by Author (2018) 
Table 4.1b Impulse Response Function of Economic Growth in Nigeria $G D P_{t}=1.49636 G D P_{t-1}-0.57041 E N V P_{t-1}+6.644101 P O P_{t-1}+15.02648 L E X P_{t-1}$

\begin{tabular}{|l|l|l|l|l|}
\hline \multicolumn{2}{|l|}{ Response of LOG(GDP): } & LOG(LEXP) & LOG(ENVP) & LOG(GDP) \\
\hline Period & LOG(POP) & -0.05578 & $\mathbf{0 . 0 0 0 6 5}$ & 0.13619 \\
\hline 1 & 0.05754 & -0.14956 & $\mathbf{- 0 . 0 4 2 1 8}$ & 0.07472 \\
\hline 2 & 0.03535 & -0.04065 & $\mathbf{- 0 . 0 3 3 7 0}$ & 0.08698 \\
\hline 3 & 0.18129 & 0.69713 & $\mathbf{- 0 . 0 0 1 2 1}$ & 0.11321 \\
\hline 4 & 0.48645 & -0.64273 & $\mathbf{0 . 0 3 4 0 8}$ & -0.13164 \\
\hline 5 & -0.21275 & -0.70174 & $\mathbf{- 0 . 0 6 8 6 7}$ & 0.11171 \\
\hline 6 & -0.06608 & 3.18168 & $\mathbf{- 0 . 0 9 6 7 1}$ & 0.28326 \\
\hline 7 & 1.45171 & -3.18687 & $\mathbf{0 . 3 7 0 3 6}$ & -0.71552 \\
\hline 9 & -1.75457 & -4.53564 & $\mathbf{- 0 . 2 2 0 0 2}$ & 0.51727 \\
\hline 10 & -1.41195 & 15.02648 & $\mathbf{- 0 . 5 7 0 4 1}$ & 1.49636 \\
\hline
\end{tabular}

\section{Source: VECM result and Compiled by Author (2018)}

To achieve the objective of forecasting the effect of reducing/increasing ENVP on GDP and human health, the VECM system model variables are further conditioned (changed) deliberately by a given per cent $(10 \%, 20 \%$ and $26 \%)$ from 2000 to 2015 periods. The VECM system equations are further solved based on the new changes and the results are presented below. A $10 \%$ reduction scenario forecast of environmental pollution as shown in fig 1 below leads to a consistent increased life expectancy at birth of the country and increased GDP as well as population. This indicates that a reduction in environmental pollution will improve the health of Nigerians and also enhance a better economy.

A further $20 \%$ scenario reduction forecast of environmental pollution shown in fig 2 below leads to a more consistent increased life expectancy at birth of the country and increased GDP as well as population. This indicates that a reduction in environmental pollution will improve the health of Nigerians and also enhance a better economy. To corroborate the effect of NNPC $26 \%$ reduction in gas flaring in Nigeria, a $26 \%$ scenario reduction forecast of environmental pollution illustrated in fig 3 below indicates a much more consistent increased life expectancy at birth of the country and increased GDP as well as population. This indicates that a reduction in environmental pollution will improve the health of Nigerians and also enhance a better economy. 
ENVP

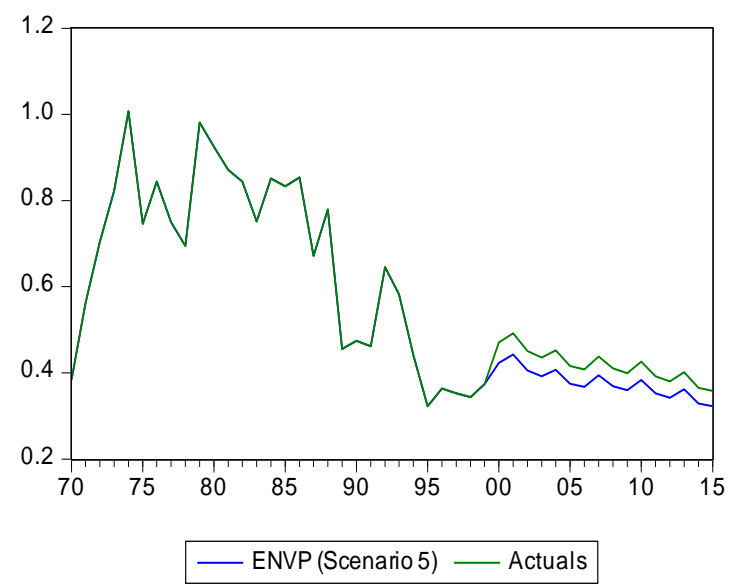

LEXP

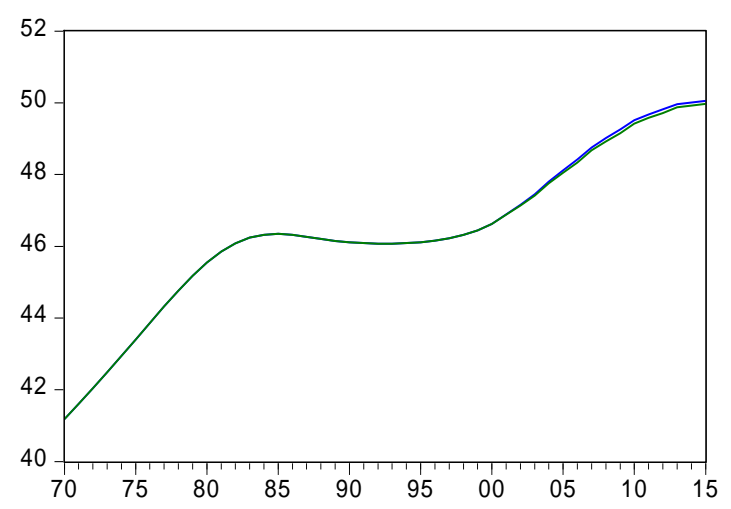

— LEXP (Scenario 5) — Actuals
GDP

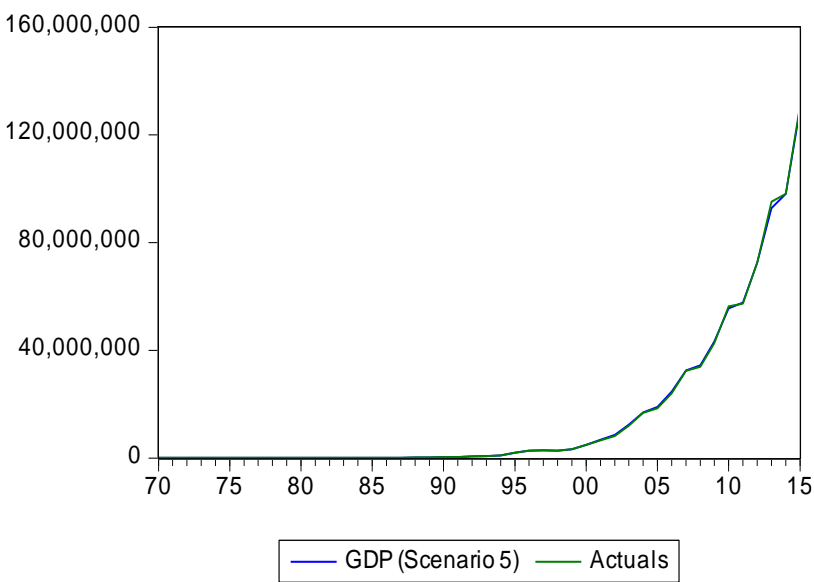

POP

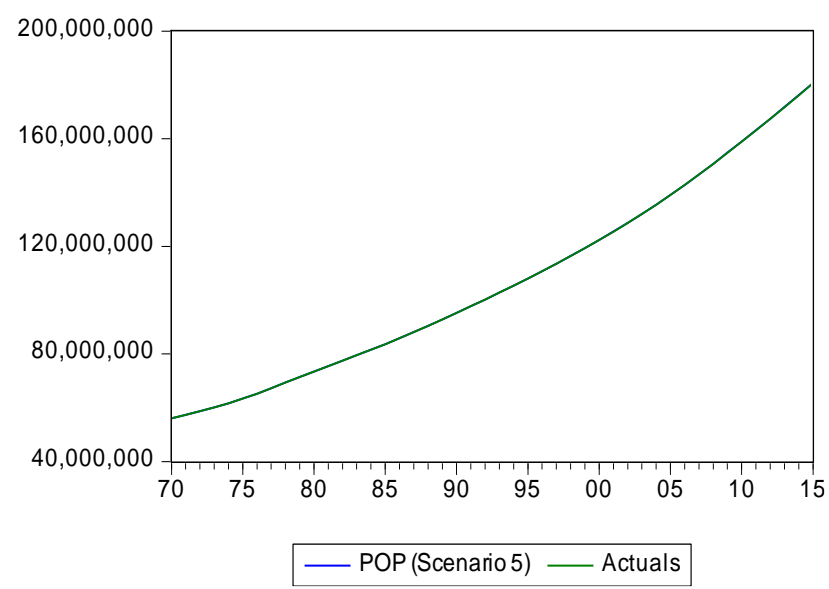

Figure 1: Forecast of $10 \%$ reduction in environmental pollution from 2000 - 2015

Source: VECM Scenario Analysis and Compiled by Author (2018) 
ENVP

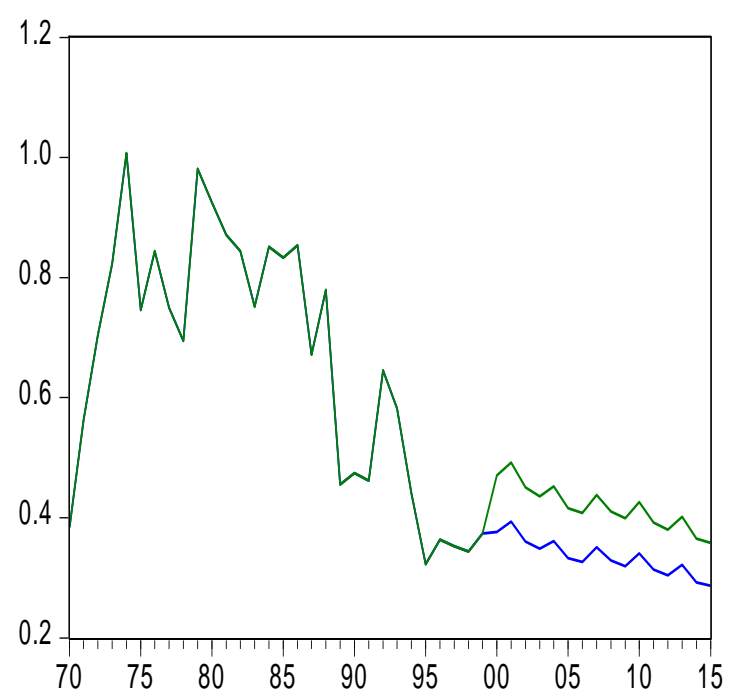

_ ENVP(Scenario 11) _ Actuals

LEXP

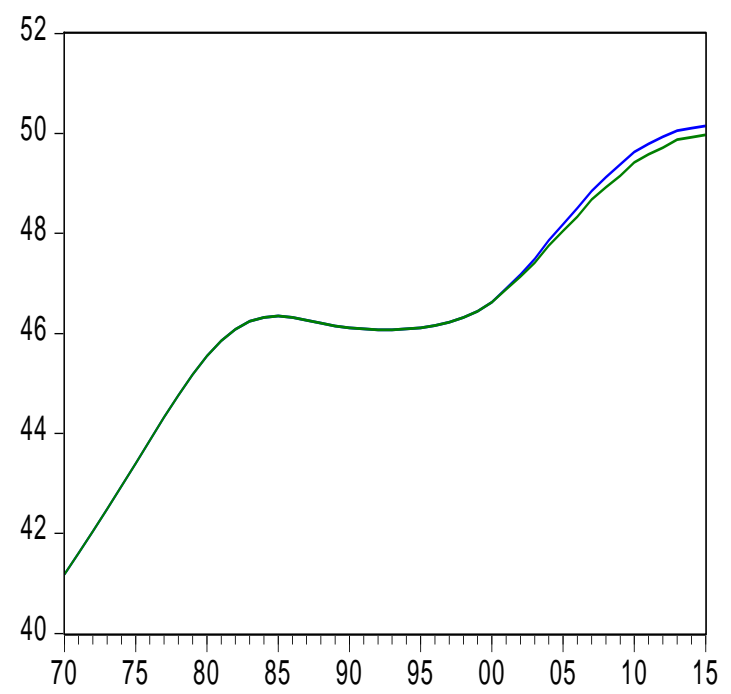

GDP

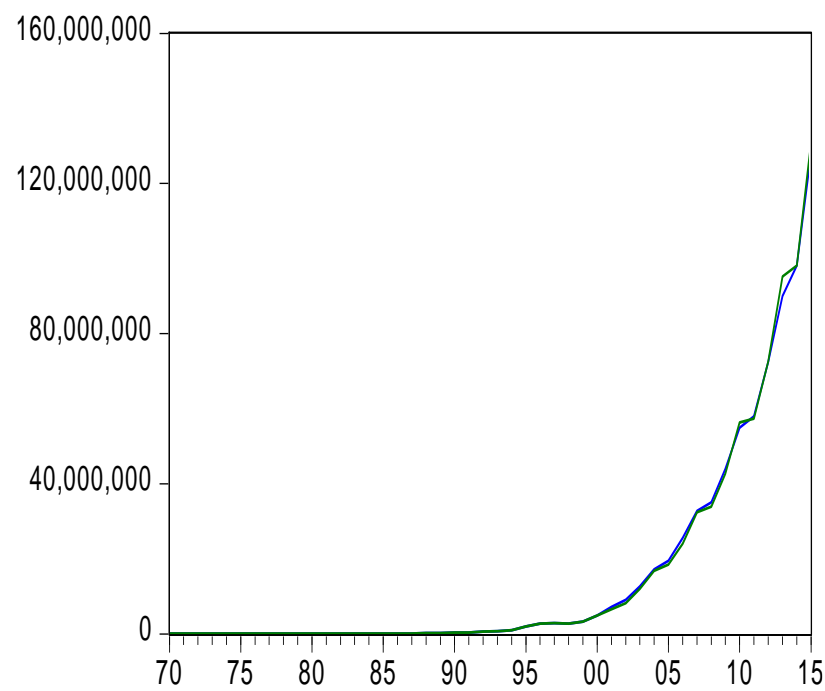

— GDP (Scenario 11) _ Actuals

POP

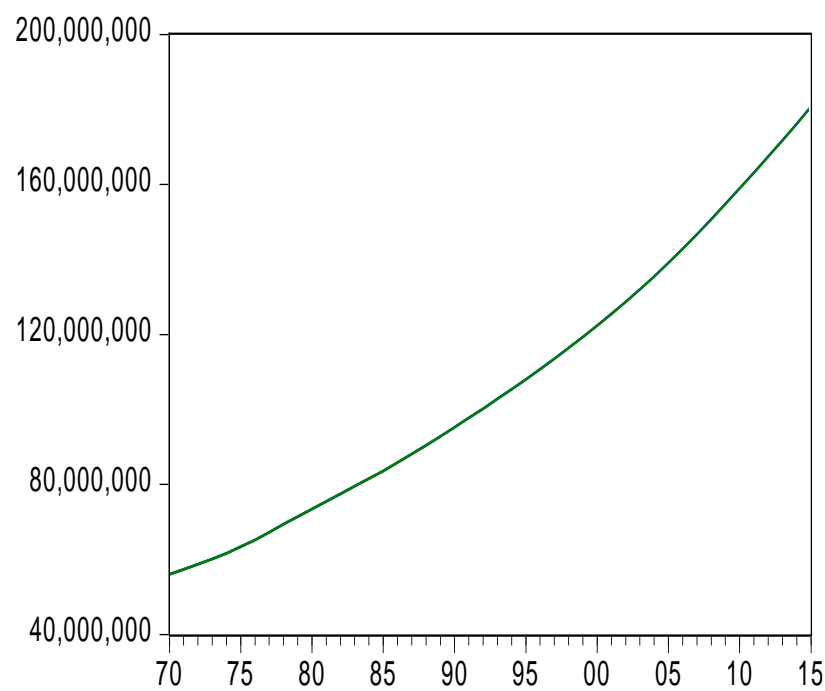

— POP(Scenario 11) _ Actuals

Figure 2: Forecast of 20\% reduction in Nigerian Carbon Emission per capita from 2000 - 2015

Source: VECM Scenario Analysis and Compiled by Author (2018) 
ENVP

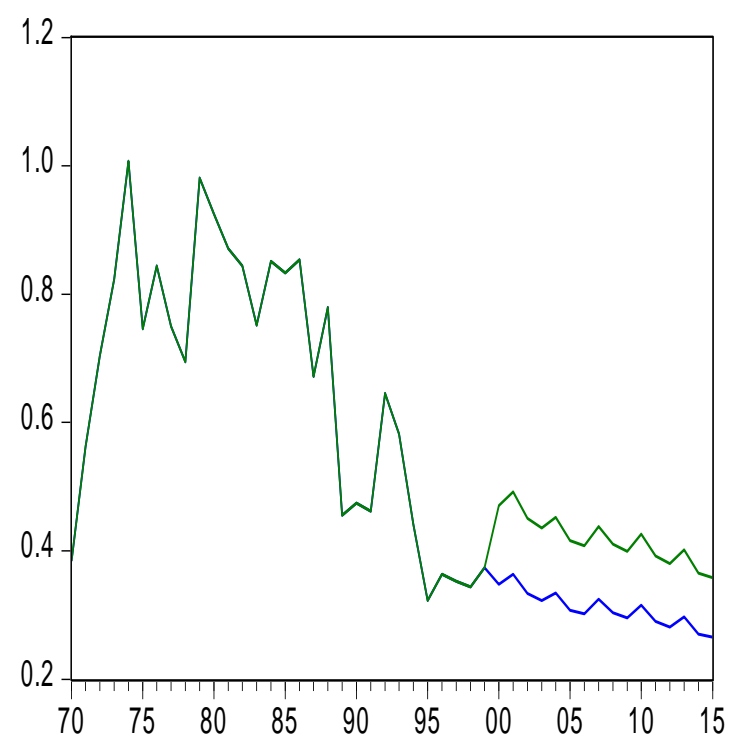

- ENVP(Scenario 12) — Actuals

LEXP

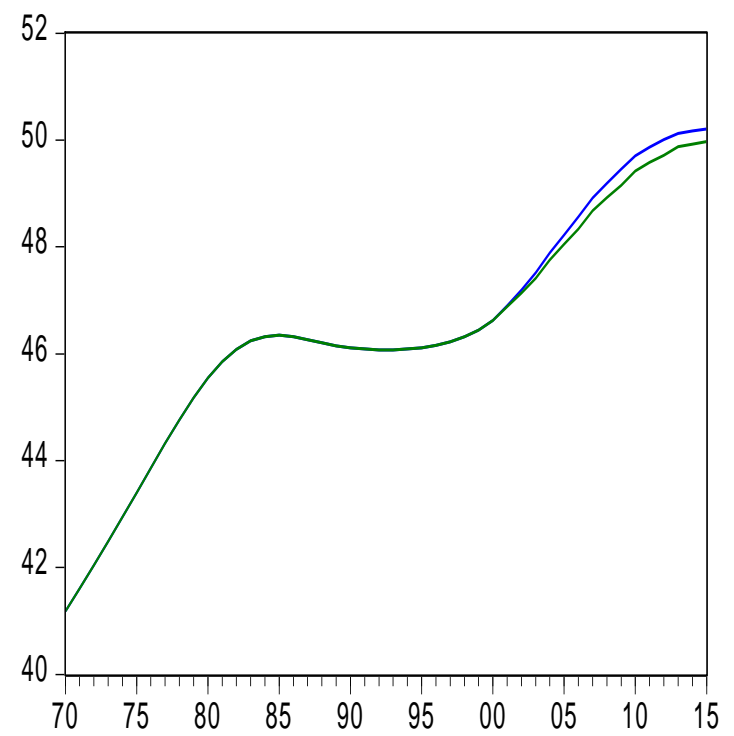

GDP

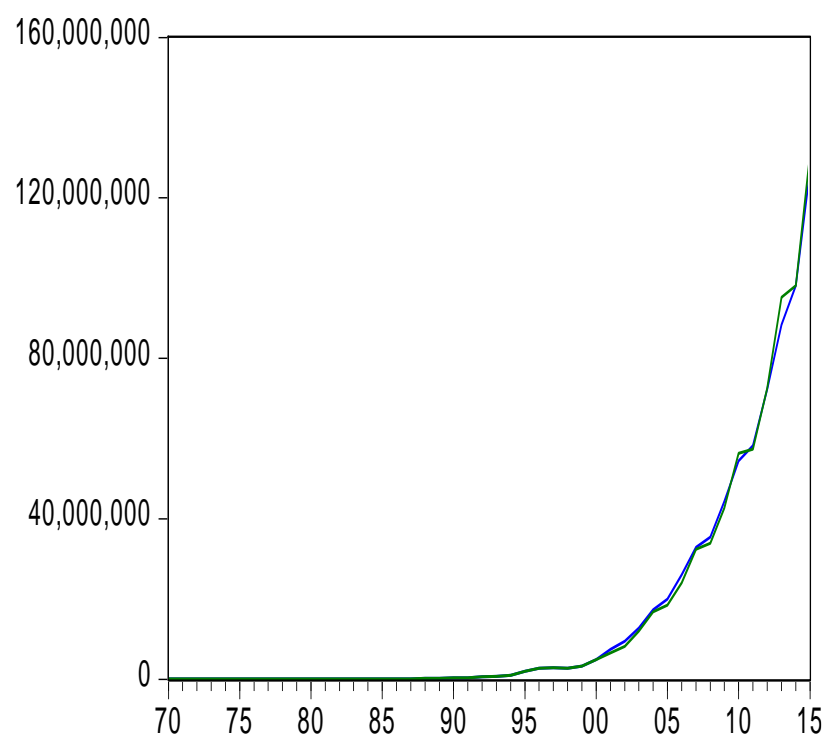

— GDP (Scenario 12) _ Actuals

POP

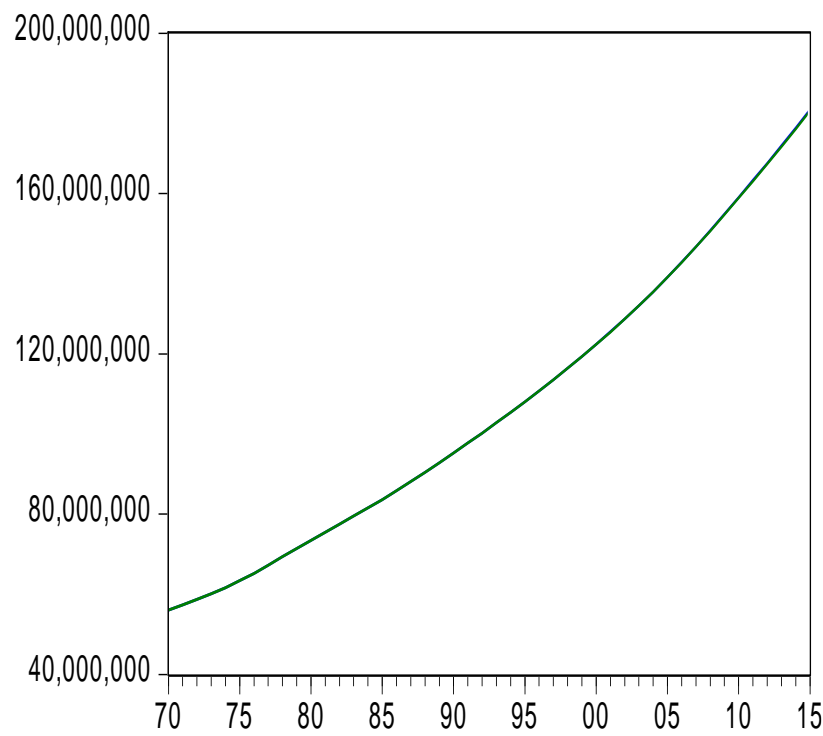

Figure 3: Forecast of 26\% reduction in Nigerian Carbon Emission per capita from 2000 - 2015

\section{Source: VECM Scenario Analysis and Compiled by Author (2018)}

The results of the cointegration analysis shows that a long-run relationship existed among the variables in the model, indicating that linearly independent combinations of the non-stationary variables were stationary in the long-run.

A scenario forecast whether if indeed a policy effort to reduce carbon emission of each individual $\left(\mathrm{CO}_{2}\right.$ emissions per capita) in the country would increase the number of years each individual lives (life expectancy at birth), increase population and economic growth in the country. To achieve this objective in the study, the VECM system model variables are further conditioned (changed) deliberately by 
a given per cent $(10 \%, 20 \%$ and $26 \%)$ from 2000 to 2015 periods and it was that the lower the environmental pollution, the higher the other variables (GDP, Life expectancy at birth and population) in the study.

\section{CONCLUSION}

The study therefore concludes that Nigeria environmental laws needs to be updated to ensure that present economic activities do not jeopardize future potentials or economic activities (sustainable development) in the country. Besides updating our environmental laws, there is need to put the requisite machineries in place to ensure enforcing these laws to actual achieve the set objective of protecting the environment amidst economic activities like oil exploration in the country. The study also concludes that life expectancy at birth, population and economic growth responds inversely to environmental pollution.

\section{REFERENCES}

[1]. Kuznets, S. Economic growth and income inequality. American Economic Review, 45(1), 1-28.,1995.

[2]. Mally, K. V. Regional differences in Slovenia from the viewpoint of achieving Europe's Sustainable Development, Acta geographica Slovenica, 58-2, 2018, 31-46,2018.

[3]. Oladeji S. I. and Adebayo A. A. The Scope of Human Resources Sustainable Development under the Adjustment Programme in Nigeria, NES (ed.) Beyond Adjustment: the Management of the Nigerian Economy, Selected Papers of the Annual Conference, the Nigerian Economic Society (NES), Ibadan.1996.

[4]. Ekperiware M. C. Dynamics of Human Capital Formation and Long-run Economic Growth in Nigeria (1970-2014), $\mathrm{PhD}$ thesis from the department of economics, Obafemi Awolowo University (OAU), Ile-Ife, Nigeria.2018

[5]. Stevens C. Measuring Sustainable Development, STATISTICS BRIEF, OECD, No. 10 September, 2005, https://www.oecd.org/std/35407580.pdf

[6]. Adejumo A. V. and Adejumo P. O. Prospects for Achieving Sustainable Development Through the Millennium Development Goals in Nigeria. European Journal of Sustainable Development, 3, 1, 33-46,2014.

[7]. Samet, J.M. Marbury, M.C. and Spengler, J.D. "Health effects and sources of indoor air pollution. part i," American Review of Respiratory Disease, vol. 136, no. 6, pp. 1486-1508.2014.

[8]. Doherty, R. M. (2015), “Atmospheric chemistry: Ozone pollution from near and far,” Nature Geoscience, vol. 8, no. 9, pp. 664-665.2015.

[9]. Shafik, N., \&Bandyopadhyay, S. Economic growth and environmental quality: Time series and crosscountry evidence, World Bank Policy Research Working Paper, WPS 904.1992

[10]. Gyarmati-Szab’o, J., Bogachev, L. V. and Chen, H. Nonstationary POT modelling of air pollution concentrations: Statistical analysis of the traffic and meteorological impact arXiv:1610.06195v2 [stat.AP] 29 May 2017, https://arxiv.org/pdf/1610.06195.pdf

[11]. Gül, H., Gaga, E. O., Döğeroğlu, T., Özden, Ö., Ayvaz, Ö., Özel, S. and Güngör, G. Respiratory health symptoms among students exposed to different levels of air pollution in a Turkish city. Int $\mathrm{J}$ Environ Res Public Health. Apr;8(4):1110-25.2011.

[12]. Yazdi, S. K., Tahmasebi Z. and Mastorakis, N. . Public Healthcare Expenditure and Environmental quality in Iran, Recent Advances in Applied Economics, ISBN: 978-960-474-394-0. 2012.

[13]. Greiner, R., Herr, A., Brodie, J. and Haynes, D. A multi-criteria approach to Great Barrier Reef catchment (Queensland, Australia) diffuse-source pollution problem,. Marine Pollution Bulletin 51, pp. 128-137,2005.

[14]. Isola, W.A. and Mesagan, E.P. Impact of Oil Production on HumanCondition in Nigeria, MPRA Paper No. 67784, posted 13,2015.

[15]. Gutierrez, M. J. Dynamic inefficiency in an overlapping generation economy with pollution and health costs. J. Public Econ. Theory 10 (4), 563-594.2008. 
[16]. Panayotou, T. Demystifying the environmental Kuznets curve: turning a black box into a policy tool. Environment and development economics, 2(04), 465-484.1997.

[17]. He, j. and Richard, P,. Environmental Kuznets Curve for CO2 in Canada, Groupe de Recherche en Économie et Développement International, Cahier de recherche / Working Paper 09-13,2009.

[18]. Stern, D. I. and Common, M. S. Is there an environmental Kuznets curve for sulfur? Journal of Environmental Economics and Environmental Management, 41: 162-178., 2011.

[19]. Hassan, S. A., Zaman, K. and Gul, S. The Relationship between Growth-Inequality-Poverty Triangle and Environmental Degradation: Unveiling the Reality,. Arab Economics and Business Journal 10 57-71,2011.

[20]. Akbostancı, E., Türüt-Aşık, S., and Tunç, G. İ. The relationship between income and environment in Turkey: Is there an environmental Kuznets curve?. Energy Policy, 37(3), 861-867,2009.

[21]. Mizushima, A.. Population Aging and Economic Growth: The Effect of Health Expenditure, European University Institute, Series/Number: EUI ECO; 35, 2008.

[22]. Christiano L. J. (2012). Christopher A. Sims and Vector Autoregressions,. Scand. J. of Economics 114(4), 2012. 1082-1104, 2012, DOI: 10.1111/j.1467-9442.2012.01737.x 